\title{
The Development of the Routing Pattern of the Backbone Data Transmission Network for the Automation of the Krasnoyarsk Railway
}

\author{
Sergey Victorovich Makarov \\ Department of Information Systems \\ Yurga Technological Institute of the \\ Tomsk Polytechnic University \\ Jurga, Russia
}

\author{
Faridun Abdulnazarov \\ Department of Information Systems \\ Yurga Technological Institute of the \\ Tomsk Polytechnic University \\ Jurga, Russia
}

\author{
Omurbek Anarbekov \\ Department of Information Systems \\ Yurga Technological Institute of the \\ Tomsk Polytechnic University \\ Jurga, Russia
}

\begin{abstract}
The paper deals with the data transmission network of the Krasnoyarsk Railway, its structure, the topology of data transmission and the routing protocol, which supports its operation, as well as the specifics of data transmission networking. The combination of the railway automation applications and the data transmission network make up the automation systems, making it possible to improve performance, increase the freight traffic volume, and improve the quality of passenger service. The objective of this paper is to study the existing data transmission network of the Krasnoyarsk Railway and to develop ways of its modernization, in order to improve the reliability of the network and the automated systems that use this network. It was found that the IS-IS and OSPF routing protocols have many differences, primarily due to the fact that the IS-IS protocol does not use IP addresses as paths. On the one hand, it makes it possible to use the IS-IS protocol for the operation in IPv6 networks, whereas OSPF version 2 doesn't provide this opportunity; therefore, OSPF version 3 was developed to solve this problem. However, on the other hand, in case of using IPv4, the routing configuration by means of the IS-IS protocol will imply the need to study a significant volume of information and use unusual methods of routing configuration.
\end{abstract}

\section{Keywords-Router; Topology; IS-IS protocol; OSPF protocol}

\section{INTRODUCTION}

The importance of the rail road is stipulated by large dimensions of the country, absence of all-year river traffic, and absence of river traffic from West to East. Thus, the rail road fulfills an important function, that of delivering cargoes and passengers all around the country and provides $43.2 \%$ of total cargo turnover and approximately 33\% of passengers turnover in Russia. At present, branches of JSC "Russian Railways" are processing sufficient volume of information on the jobs completed, as well as compiling necessary jobs timetable to satisfy the demands of the consumers. The compiled jobs time-table is to be coordinated with the head office located in Moscow, and also to be distributed among the branches, directorates, companies, and stations engaged into performing the jobs as per compiled working plans. The united data transfer network is used for information distributing. All automated systems consist of automation application and data transfer network, which is necessary for operation of the system. The data transfer network is the basis of the automated systems, and its failure-free operation is very important for the automation system in general. Failure in the data transfer network operation can make absolutely senseless operation of the automation application in case, if there is no possibility to transfer the information, processed by automation application, on operation of the company servicing the rail road, station or directorate. The data transfer can be sufficiently delayed when transferring large data volumes using voice communication or low speed mobile data transfer network. When functionality of the data transfer network is recovered, the importance of collected information can be already lost. Also, improper operation of the data transfer network can lead to partial loss of the information and consequently one cargo rail car will be reserved for various customers, or the seat in the passenger car will be occupied by two different passengers having in their possession the tickets bought using the Internet-service, because the information on one of them was not delivered to the united data base of JSC "Russian Railways" and the seat was not flagged as occupied one, so a ticket for the seat was sold second time.

Therefore, the data transfer network is an important element of operation of the automated systems used by JSC "Russian Railways", and properly designed or modernized data transfer network plays important role in functioning the company "Russian Railway" in general and its separate branches as well. JSC Russian Railways (JSC RZD) is Russia's largest railway company; it also ranks among the top three major railway corporations in the world. The Krasnoyarsk Railway is a branch of JSC "Russian railways". To ensure the effective work of JSC "Russian railways", various automated systems are used. The number of such systems is about 150 to 200 ; it is difficult to determine the exact number, as some branches and services apply their own automation systems to improve the performance of subdivisions. In particular, the following systems can be mentioned: ASOUP (Automated Traffic Control System); ETRAN (Electronic Waybill); Express-3; ASKUE (Automated system of commercial power accounting).

The data transmission network of the Krasnoyarsk Railway covers all stations and enterprises serving the railway. Depending on the size of a station, its geographical location and functions, it has a network with various bandwidth, from $2 \mathrm{MB} / \mathrm{s}$, organized using the existing 
physical lines, up to $1 \mathrm{~GB} / \mathrm{s}$, organized with the use of fiberoptic network; a network with a bandwidth of up to $1 \mathrm{~GB} / \mathrm{s}$ necessarily connects peripheral transport hubs and the regional hub, as well as major stations (Figure 1).

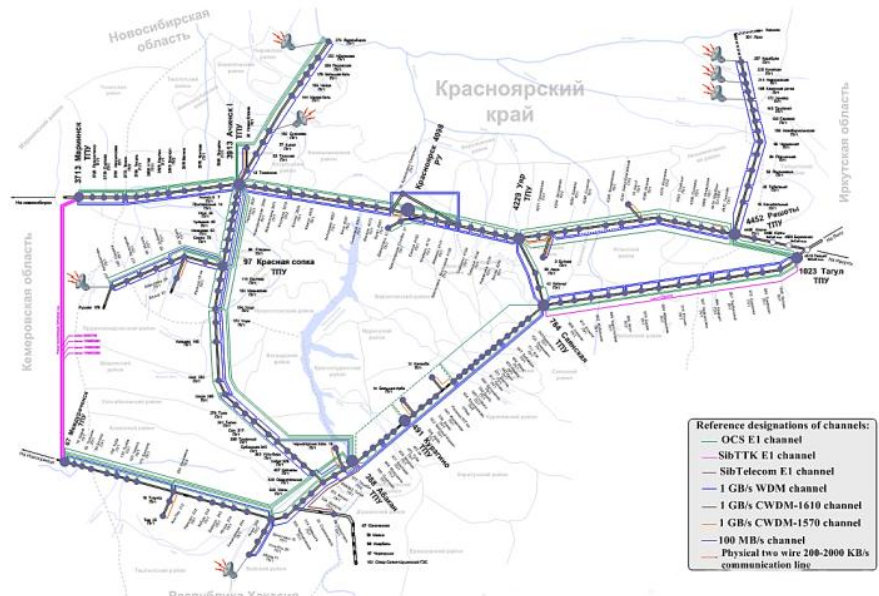

Fig. 1. Topological diagram of the data transmission network of the Krasnoyarsk Railway

\section{Methodology}

\section{A. The method of data addressing of the Krasnoyarsk Railway}

The data transmission network of the Krasnoyarsk Railway uses the OSPF routing protocol. The OSPF protocol makes it possible to segment the network into many areas, but at the same time, all the areas will be merged into a single routing domain, or, in other words, a single autonomous system [1].

All IP address space, available to JSC RZD, is divided between different paths by individual segments. This division makes it possible to order the distribution of information and simplify the configuration of addressing for JSC "RZD" in general and for its individual branches, as well as for different areas of the data transmission network. As each device (printers, terminals, computers) in the network must have a unique IP address in order to be able to communicate with other devices, the network must have an adequate range of IP addresses, from which an IP address for each device can be allocated. The Krasnoyarsk Railway has a set of IP addresses, allocated from the total IP address pool, available to JSC RZD, which is used by all devices for data transmission, both within the Krasnoyarsk Railway and for connection with other roads. Besides, each of the pools is divided into 5 VPNs (Virtual Private Network is the generic name of technologies that provide one or more network connections [logical network] over a different network), which perform different functions, including data transmission network management, maintenance of automated systems Express 3, ETRAN, etc.

Each station is equipped with networks, belonging to all three pools, and at least three types of VPNs: Legacy (data transmission network management), Express (System Express 3 ), VPN 2 (other). Thus, the number of routes, which should be stored by each router, at each station is approximately equal to

$$
1017 \cdot 3 \cdot 3=9153
$$

With allowance for the VPNs, which are necessarily present at all communications centers, we get the number 9153 , but it should be remembered that some stations may also be equipped with VPNs required for the servicing of commercial subscribers and organizing video monitoring. These VPNs should also be recorded in the memory of each router, which further loads the routers installed at communications centers, and the resulting number of networks may differ considerably from the calculated minimum. Besides, the number of networks is constantly changing, so the resulting number of networks can vary within $10 \%$ [2].

To determine the amount of memory occupied by each entry of the topology table, a routing testbed was used, the diagram of which is presented in Figure 2.

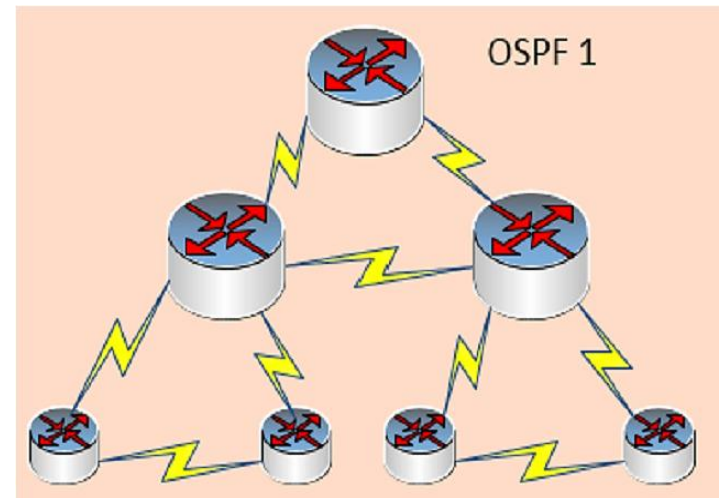

Fig. 2. The diagram of the routing testbed

To calculate the amount of memory occupied by the entries of routes, it is necessary to use the show IP route summary command. For various topologies, having different number of subnets, the results of the command execution are shown in Table 1.

TABLE I. The Amount OF MEMory OCCUPIED by ONE SUbNeT

\begin{tabular}{|l|l|l|l|l|l|}
\hline $\begin{array}{c}\text { Route } \\
\text { Source }\end{array}$ & Networks & Subnets & Overhead & $\begin{array}{c}\text { The } \\
\text { Memory } \\
\text { (bytes) }\end{array}$ & $\begin{array}{c}\text { Tmount } \\
\text { of } \\
\text { memory } \\
\text { required } \\
\text { to store } \\
\text { one entry } \\
\text { (bytes) }\end{array}$ \\
\hline ospf 1 & 0 & 1 & 72 & 136 & 136 \\
\hline ospf 1 & 0 & 2 & 144 & 272 & 136 \\
\hline ospf 1 & 0 & 4 & 288 & 544 & 136 \\
\hline ospf 1 & 0 & 6 & 432 & 816 & 136 \\
\hline ospf 1 & 0 & 7 & 504 & 952 & 136 \\
\hline ospf 1 & 0 & 9 & 648 & 1224 & 136 \\
\hline
\end{tabular}

The table shows that each new subnet occupies 136 bytes in the memory of the router. Thus, to store 9153 records, the following amount of memory is required:

$$
9153 \cdot 136=1244808 \text { byte }=1.18 \text { Mbytes }
$$


Besides, a relatively equal amount of memory is occupied by the topology tables on each device; thus, reducing the size of topology tables will also result in the reduction of the amount of occupied memory, which will have a beneficial impact on the performance of installed equipment. The reduction of the amount of memory, occupied by subnets, will provide an opportunity to continue using the installed routers in case of network expansion, which will make it possible to reduce the cost of maintaining network health [3].

\section{RESULTS}

\section{A. Core OSPF routing protocol}

The OSPF routing protocol ensures the transmission of IP packets based on the IP address of the recipient of the packet; the IP addresses of the recipients of the packet are defined in the IP packet header. In the process of sending an IP packet, its content is not changed. That is, no encapsulation into other packets takes place [4]. To exchange information about the communication channels which are known to the router, small packets called link state advertisements (LSA) are used [5].

\section{B. Address table and OSPF areas}

The Krasnoyarsk Railway uses the OSPF routing protocol for data transmission. That is, the network covering the entire railway is divided into separate areas, but at the same time the network as a whole is a single routing domain. In addition to individual areas, covering specific parts of the railroad, there is also an area 0, which includes all area border routers and ensures distribution of routing information between other areas. The division of the entire data transmission network into different areas is shown in Figure 3.

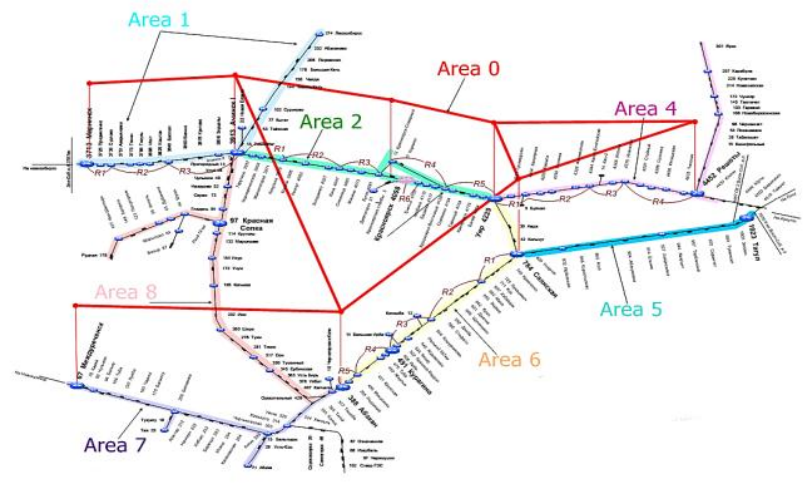

Fig. 3. OSPF areas of the Krasnoyarsk railway

The entire data transmission network is divided into 8 areas (area 3 is absent, as it was merged with area 4). The division is based on the geographical distribution of the data transmission network. Area 0, unlike other areas, topographically covers the entire data transmission network and performs the functions of communication between an all the other areas, ensuring fast data transfer between areas. Redistribution of routing information should be used if there are different routing protocols in the data transmission network [6]. Even if different routing protocols are running on one router, it does not mean that the router will automatically start transferring information from one protocol to another. The reason for that is that different routing protocols use different metrics, which makes it impossible to automatically transfer information from one protocol to another. The redistribution of routing information can be either carried out in one direction, or be bilateral. Bilateral distribution is not always possible, for example, in case of using outdated equipment in a certain network segment, which does not support the core routing protocol. In this case, the process of the redistribution of routing information to this segment of the network can be configured, while inverted distribution can lead to the overload of the equipment. Besides, the bilateral distribution of routing information can lead to the destruction of the metric domain and the formation of routing loops. Various routing protocols use different algorithms for calculating metrics [7]. However, regardless of the specific algorithm for calculating metrics, metrics of all routing protocols have one common property - they increase linearly with the increase of the number of transitions on the path from the recipient network.

Formally, the cumulative nature of the metrics can be described by the following expression (3).

$$
\forall d \text { and } d^{\prime}, \text { where } d^{\prime}>d, M\left(d^{\prime}\right)>M(d)
$$

where $d$ and $d^{\prime}$ - the number of transitions on the path from the recipient network. $M(x)$ is a function of the metric.

Given this common property of the metrics of routing protocols, it is possible to define the metric domain of a routing protocol as a part of the data transmission network, in which the metrics of a routing protocol reflect the distance to the recipient network and satisfy the (3). Metrics are calculated in accordance with the algorithm, prescribed by the routing protocol, which is running on routers [8]. In other words, any router within the metric domain of the routing protocol calculates the metrics of routes to the recipient networks within the metric domain in accordance with the algorithm, prescribed by the routing protocol. If a router uses any other algorithm to calculate the metric of a route to the recipient network, then this router is located beyond the metric domain, to which the recipient network belongs.

To enable the mechanism of the redistribution of routing information, the redistribute command is used. The general syntax of the command is shown below.

(config-router)\#redistribute protocol [metric metricvalue][tag tag-value] [route-map map-tag]

(config-router)\# no redistribute protocol [metric metricvalue][tag tag-value] [route-map map-tag]

The parameters of the redistribute command are shown in Table 2.

TABLE II. THE PARAMETERS OF THE REDISTRIBUTE COMMAND

\begin{tabular}{|l|l|}
\hline \multicolumn{1}{|c|}{ Parameter } & \multicolumn{1}{|c|}{ Description } \\
\hline Protocol & Routing information source \\
\hline metric metric-value & The metric, assigned for redistributed routes \\
\hline tag tag-value & $\begin{array}{l}\text { A tag, assigned for using in the route } \\
\text { redistribution control }\end{array}$ \\
\hline route-map map-tag & The name of the route map used for redistribution \\
\hline
\end{tabular}


Each new routing protocol should have its own number. To order the numbering of OSPF processes, the following rule is applied: the first digit is the number of the OSPF area, the second digit is the number of the segment of the considered area, the third digit is the number of VRF [9]. The routing processes, which are to be configured for area 1, are specified in Table 3. Configuring these routing processes makes it possible to separate both segments of area 1 from the general network and transfer the information to the neighboring segments; accordingly, their addresses will be stored only by the routers installed at peripheral transport hubs, whereas the internal routers will only know the routes to the routers, located in the same segment, and a default route to the routers of peripheral transport hubs.

TABLE III. The Routing Processes of AREA 1

\begin{tabular}{|l|l|l|l|}
\hline Areas & $\begin{array}{c}\text { The routing } \\
\text { process for the } \\
\text { Express } \\
\text { system }\end{array}$ & $\begin{array}{c}\text { The routing } \\
\text { process for the } \\
\text { control process }\end{array}$ & $\begin{array}{c}\text { The routing } \\
\text { process for } \\
\text { other } \\
\text { processes }\end{array}$ \\
\hline Segment 1 & OSPF111 & OSPF1188 & OSPF112 \\
\hline Segment 2 & OSPF121 & OSPF1288 & OSPF122 \\
\hline
\end{tabular}

The routing processes, which are to be configured at peripheral transport hubs, located at Achinsk and Uyar railway stations, as well as at the regional transport hub, located at Krasnoyarsk railway station, are specified in Table 4.

TABLE IV.

The Routing Processes of AREa 2

\begin{tabular}{|l|l|l|l|}
\hline Areas & $\begin{array}{c}\text { The routing } \\
\text { process for the } \\
\text { Express } \\
\text { system }\end{array}$ & $\begin{array}{c}\text { The routing } \\
\text { process for the } \\
\text { control process }\end{array}$ & $\begin{array}{c}\text { The routing } \\
\text { process for } \\
\text { other } \\
\text { processes }\end{array}$ \\
\hline Segment 1 & OSPF211 & OSPF2188 & OSPF212 \\
\hline Segment 2 & OSPF221 & OSPF2288 & OSPF222 \\
\hline
\end{tabular}

The routing processes, which are to be configured to ensure the correct operation of the mechanism of the redistribution of routing information, are specified in Table 5.

TABLE V.

The Routing PRocesses of AREA 4

\begin{tabular}{|l|l|l|l|}
\hline Areas & $\begin{array}{c}\text { The routing } \\
\text { process for the } \\
\text { Express } \\
\text { system }\end{array}$ & $\begin{array}{c}\text { The routing } \\
\text { process for the } \\
\text { control process }\end{array}$ & $\begin{array}{c}\text { The routing } \\
\text { process for } \\
\text { other } \\
\text { processes }\end{array}$ \\
\hline Segment 1 & OSPF411 & OSPF4188 & OSPF412 \\
\hline Segment 2 & OSPF421 & OSPF4288 & OSPF422 \\
\hline
\end{tabular}

To ensure the correct operation of the mechanism of the redistribution of routing information at peripheral transport hubs, located at Sayanskaya and Tagul railway stations, it is necessary to configure OSPF routing protocols, the names of which are listed in Table 6.

\section{TABLE VI. The Routing PROCESSES OF AREA 5}

\begin{tabular}{|l|l|l|l|}
\hline Areas & $\begin{array}{c}\text { The routing } \\
\text { process for the } \\
\text { Express } \\
\text { system }\end{array}$ & $\begin{array}{c}\text { The routing } \\
\text { process for the } \\
\text { control process }\end{array}$ & $\begin{array}{c}\text { The routing } \\
\text { process for } \\
\text { other } \\
\text { processes }\end{array}$ \\
\hline Segment 1 & OSPF511 & OSPF5188 & OSPF512 \\
\hline Segment 2 & OSPF521 & OSPF5288 & OSPF522 \\
\hline
\end{tabular}

The routing processes, which are to be configured to ensure correct operation of the mechanism of the redistribution and reducing the size of the topology tables of internal routers, are specified in Table 7.

TABLE VII.

THE ROUTING PROCESSES OF AREA 6

\begin{tabular}{|l|l|l|l|}
\hline Areas & $\begin{array}{c}\text { The routing } \\
\text { process for the } \\
\text { Express } \\
\text { system }\end{array}$ & $\begin{array}{c}\text { The routing } \\
\text { process for the } \\
\text { control process }\end{array}$ & $\begin{array}{c}\text { The routing } \\
\text { process for } \\
\text { other } \\
\text { processes }\end{array}$ \\
\hline Segment 1 & OSPF611 & OSPF6188 & OSPF612 \\
\hline Segment 2 & OSPF621 & OSPF6288 & OSPF622 \\
\hline Segment 3 & OSPF631 & OSPF6388 & OSPF632 \\
\hline
\end{tabular}

The routing processes, which are to be configured to ensure the correct operation of the mechanism of the redistribution of routing information, are specified in Table 8.

TABLE VIII. The Routing Processes of AREA 7

\begin{tabular}{|c|c|c|c|}
\hline Areas & $\begin{array}{c}\text { The routing } \\
\text { process for the } \\
\text { Express } \\
\text { system }\end{array}$ & $\begin{array}{c}\text { The routing } \\
\text { process for the } \\
\text { control process }\end{array}$ & $\begin{array}{c}\text { The routing } \\
\text { process for } \\
\text { other } \\
\text { processes }\end{array}$ \\
\hline Segment 1 & OSPF711 & OSPF7188 & OSPF712 \\
\hline
\end{tabular}

The routing processes, which are to be configured at peripheral transport hubs, are specified in Table 9.

TABLE IX.

The Routing Processes of AREA 8

\begin{tabular}{|l|l|l|l|}
\hline Areas & $\begin{array}{c}\text { The routing } \\
\text { process for the } \\
\text { Express } \\
\text { system }\end{array}$ & $\begin{array}{c}\text { The routing } \\
\text { process for the } \\
\text { control process }\end{array}$ & $\begin{array}{c}\text { The routing } \\
\text { process for } \\
\text { other } \\
\text { processes }\end{array}$ \\
\hline Segment 1 & OSPF 811 & OSPF 8188 & OSPF 812 \\
\hline Segment 2 & OSPF821 & OSPF8288 & OSPF822 \\
\hline Segment 3 & OSPF831 & OSPF8388 & OSPF832 \\
\hline
\end{tabular}

An epxample of the configuration of the redistribution of routing information.

To redistribute routing information, it is necessary to configure in the processes, related to the processes of the transfer of information in the backbone area (area 0), the process of the redistribution of information from internal areas into the backbone area. An example of the configuration is shown below.

\section{\#configure terminal (config)\#router ospf 1}

\section{(config-router)\# redistribute ospf 121 metric 10 subnets}

The use of this command makes it possible to redistribute information from the internal area (in this case, the area, in which the OSPF 121 protocol operates) into the backbone area, in which the distribution of information is controlled by the OSPF 1 process.

To transfer information from the backbone area into the internal area, it is necessary to use the default-information originate command that configures a default route for the OSPF Protocol [10]. The general syntax of the command is shown below.

(config-router)\# default-information originate [always] [metric metric-value]

[metric-type type-value] [route-map map-name] 
(config-router)\# no default-information originate

The description of the parameters of the defaultinformation originate command is provided in Table 10 below.

TABLE X. THE PARAMETERS OF THE DEFAULT-INFORMATION ORIGINATE COMMAND

\begin{tabular}{|l|l|}
\hline \multicolumn{1}{|c|}{ Parameter } & \multicolumn{1}{c|}{ Description } \\
\hline Always & $\begin{array}{l}\text { Always propagate a default route, regardless of the } \\
\text { algorithms of automatic assignment of default routes in } \\
\text { the OSPF protocol }\end{array}$ \\
\hline $\begin{array}{l}\text { metric metric- } \\
\text { value }\end{array}$ & Route metric. The default value is 10 \\
\hline $\begin{array}{l}\text { metric-type } \\
\text { type-value }\end{array}$ & $\begin{array}{l}\text { The type of the external route: } \\
1-1 \text { the type of the external route } \\
2-2 \text { the type of the external route } \\
\text { The default value is 2 }\end{array}$ \\
\hline $\begin{array}{l}\text { route-map } \\
\text { map-name }\end{array}$ & $\begin{array}{l}\text { An instruction for the routing process to propagate a } \\
\text { default route, in case if the route-map condition is met }\end{array}$ \\
\hline
\end{tabular}

To configure the default route for the internal area serviced by the 121 OSPF protocol, it is necessary to use the following set of commands:

\section{\#configure terminal}

(config)\#router ospf 1

(config-router)\#default-information originate always

This is the way to configure the default route and, accordingly, the transfer of information from the OSPF protocol, used in the internal area, to the OSPF 1 protocol, related to the backbone area [11]. The redistribution is required to ensure that various routing processes, for example, OSPF 1 and OSPF 121, running on one router, can exchange information, in particular, so that the OSPF 1 routing process gets information on the individual networks available to the OSPF 121 routing process. Figure 4 illustrates the process of transferring information from one area into another, or from one routing process to another.

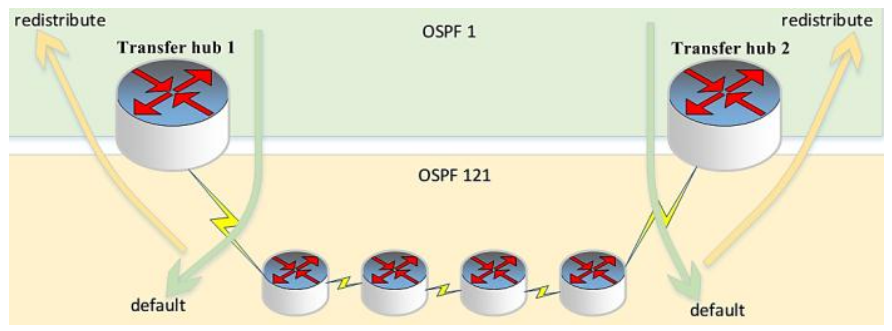

Fig. 4. The redistribution of routing information between different routing processes running on the same router

Conclusions of efficiency of the route information redistribution mechanism operation.

Redistribution of the route information for the data transfer network can allow to arrange up to 15 zones of the data transfer network and, respectively, in average by 15 times reduce volume of information stored in each of its internal routers. This reduction of stored information favorably influences the speed work of the routers installed in the remote nodes of the first and the second type, which as a rule, feature small volume of memory and can be obsolete devices, for which storing and processing large tables of routing and topology can create sufficient load. Despite evident advantages of route information redistribution mechanism, it possesses some drawbacks, limiting its use and requiring high qualification of the specialists, adjusting the mechanism. Also, it is rather complicated to support functionality of the network and to search for the failures source.

\section{Configuring Totally Stub AREas}

A stub area does not receive information about external links, imported into the OSPF routing domain. External links, which arrive into the stub area in the form of Type 5 LSAs, are automatically substituted by the area border router of the area for the default route to the area border router. The area border router has full information on all the external links in the OSPF routing domain. Stub areas can't contain area border routers of autonomous systems [12].

Totally stub area: An area, which receives neither information on external links, nor Type 3 and 4 LSAs, which are the internal links for the given OSPF routing domain. All external and inter-area routes are substituted by the area border router for the default route to the area border router [13]. Totally stub areas can't contain area border routers of autonomous systems. In a totally stub area, all the external and inter-area routes are blocked, that is, the routing table of the routers, located inside a totally stub area, contains only intraarea routes and a default route to the area border router [14]. The comparison of the processes of dissemination of the topology information in a totally stub area and a standard area is shown in Figure 5.

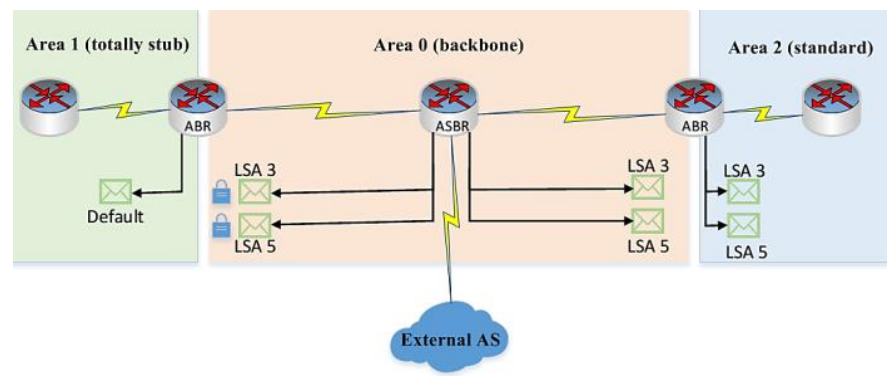

Fig. 5. The dissemination of the topology information in a totally stub area and a standard area

In addition to the rule that totally stub areas can not contain area border routers of autonomous system, a totally stub area should also comply with the following rules.

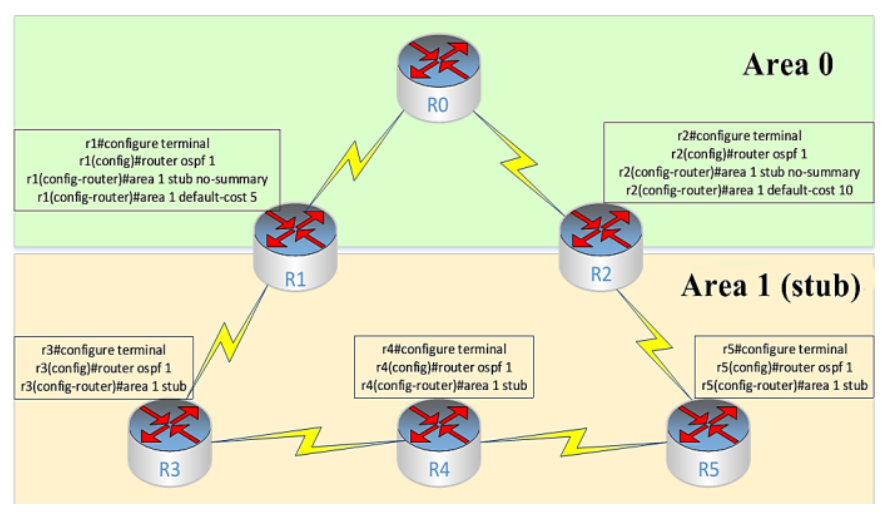

Fig. 6. An example of the configuration of a totally stub area 
- An area doesn't contain virtual channels.

- An area is not a backbone one.

- An area has one exit point to the backbone area.

For the purpose of the description of the configuration of a totally stub area, Figure 6 can be used.

To configure a totally stub area, two commands are used, which were described in detail above.

\section{area area-id default-cost cost area area-id stub [no-summary]}

It should be noted that the keyword no-summary, preventing the transfer of the inter-area Type 3 and 4 LSAs into a totally stub area, is added only in case of configuration of area border routers.

In order to confirm the effectiveness of reducing the size of routing tables in case of using totally stub areas, the emulation was carried out using testbeds, the diagrams of which are shown in Figure 7 (a) and 7 (b). Both routing schemes have two routing areas, but one of the schemes has normal areas, while the second one has a totally stub area.

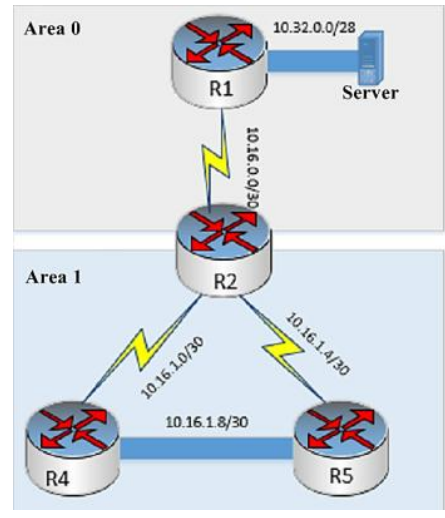

a)

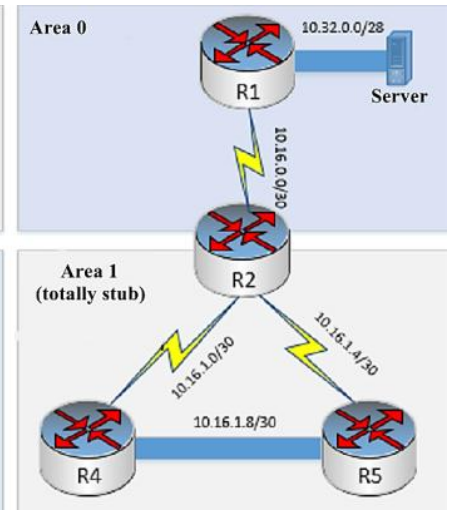

b)
Fig. 7. Diagrams of the testbeds without a totally stub area a) and with a totally stub area b)

To compare the volume of routing tables, the show ip route command was used. The results are shown below; it must be emphasized that the presented routing tables are the routing tables of the R4 router, located in the totally stub area.

Without division into areas:

R4\#show ip route

$10.0 .0 .0 / 8$ is variably subnetted, 7 subnets, 3 masks O 10.0.1.1/32 [110/65] via 10.16.1.1, 00:03:57, Serial0/0 O IA 10.0.0.1/32 [110/129] via 10.16.1.1, 00:02:16, Serial0/0 C $10.16 .1 .8 / 30$ is directly connected, FastEthernet $0 / 0$ O IA 10.16.0.0/30 [110/128] via 10.16.1.1, 00:03:56, Serial0/0 C 10.16.1.0/30 is directly connected, Serial0/0
O $10.16 .1 .4 / 30$
[110/65]
via 10.16.1.10,
00:03:57, FastEthernet $0 / 0$

O IA 10.32.0.0/28 [110/129] via 10.16.1.1, 00:02:16, Serial0/0

The OSPF routing protocol is a link state protocol, and it has accurate information on the topology of the data transmission network, on the basis of which a routing table is built [15]. The routing table for the routing process without creation of a totally stub area contains routes for all devices, as prescribed by the protocol operation algorithm. Besides, it doesn't contain a default route.

With the use of a totally stub area:

$\mathrm{R} 4$ \#show ip route

$10.0 .0 .0 / 8$ is variably subnetted, 4 subnets, 2 masks O 10.0.1.1/32 [110/65] via 10.16.1.1, 00:02:09, Serial0/0 C $10.16 .1 .8 / 30$ is directly connected, FastEthernet $0 / 0$

C $10.16 .1 .0 / 30$ is directly connected, Serial0/0

O $10.16 .1 .4 / 30[110 / 65]$ via $10.16 .1 .10, \quad 00: 02: 09$, FastEthernet $0 / 0$

O*IA 0.0.0.0/0 [110/65] via 10.16.1.1, 00:02:09, Serial0/0

In case of using a totally stub area, the routing table only contains the routes to the routers, located within this area, and a default route [16]. Even on such a small testbed, a significant reduction of the size of the routing table was observed; in case of increasing the number of the routers outside the totally stub area, the difference between the topology tables and the amount of occupied memory for routers located in the totally stub areas and those located in the generic domain, without division into areas, will only increase.

In case of the creation of totally stub areas for the entire data transmission network of the Krasnoyarsk Railway, each of the routers will have to store information not on all the 9153 networks, but only on 610 networks on the average. Thus, the average amount of occupied memory is determined by Equation (4).

$$
610 \cdot 136=82960 \text { bytes }=81.016 \text { Kbytes }
$$

The information on the amount of memory, occupied by an entry of one route, is taken from the table; this amount was calculated by means of testbed emulation with different number of networks. To store the entries of all the routes, 1215.63 Kbytes of memory are required.

The calculations show that using totally stub areas makes it possible to significantly reduce the amount of occupied memory, and also reduce the processor load by reducing the amount of processed information.

Conclusions on the efficiency of using completely deadend zones.

Use of completely dead-end zones allows to reduce sufficiently the tables of routing and the tables of topology being stored in the access level routers, as well as to divide the whole data transfer network into several segments, existing topology can be divided maximum into 15 segments. This leads to reduction of load on the routers and provides possibility to use existing equipment even when enhancing the data transfer network. Increasing the data transfer network in no way influences the routers of the lower access level, because they are not connected with the routers irrelevant to this completely dead-end zone. Besides the evident advantages, the use of completely dead-end zones brings some 
disadvantages, for instance - impossibility of flexible change of completely dead-end zones.

\section{USING THE IS-IS ROUTING PROTOCOL}

Along with the possible ways of changing the OSPF routing protocol, used in the data transmission network of the Krasnoyarsk Railway, the possibility of using other routing protocols, for example, the more advanced IS-IS protocol, should also be considered. The IS-IS routing protocol, as well as the OSPF protocol, is a link state protocol [17]. That is, both protocols are characterized by using the same algorithm for searching the shortest path to other routers in the network, as well as the fast convergence of networks, i.e. the ability to quickly find alternative routes to devices belonging to the network, in case of sudden changes in the network topology [18]. The route metric in the OSPF and IS-IS protocols has some differences. For the IS-IS Protocol, as well as for the OSPF protocol, the metric is a number without dimension, and the route metric is calculated as the sum of the metrics of its constituent channels. However, in the IS-IS protocol, it is also possible to set three additional metrics: "delay", showing the length of the delay in the channel, "expense", showing the communication costs, and "error", showing the error rate in the channel [19].

When operating the routing protocol IS-IS, all the routers are divided into 3 levels as follows.

- Level 1 (analogue to in-zone routers in OSPF-protocol) - the routers knowing the routes inside the zone they are relevant to.

- Level 2 (analogues to OSPF-protocol zone 0 routersthe routers storing the information on the routes between the zones.

- Level 1-2 (analogue of the border routers in OSPFprotocol) - the routers knowing the routes between the zones, as well as within the zone they belong to.

The routers of level 1 can transfer information only to the routers of the first level, belonging to the same zone of data transfer network, same as the routers of the second level can exchange information only with the routers of level 2 . It is the routers of 1-2 level which are used to install the communication between them; besides, these routers can transfer information to other routers of 1-2 level.

The important difference from OSPF-protocol is in the fact that the routers of 1-2 level are located in some network zone but are not located between the zone 0 and the zone where they transfer information to. The differences are vividly illustrated by the Figure 8 and 9 .

The Figure 8 presents connection of the routers relevant to three zones, at that the zones 1 and 2 contain the routers of user's access level routers, the zone 0 contains the router which is the basic one and which is redistributing the information between the zones 1 and 2 . The routers R2 and R3 are the border routers and connect the basic zone with the zones 1 and 2; these routers do not belong to any detailed zone.

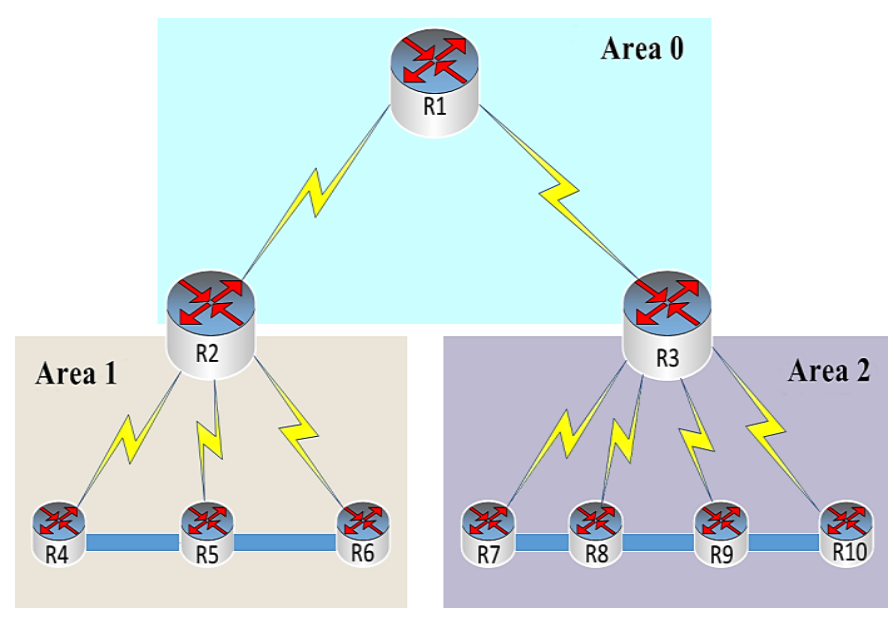

Fig. 8. Connecting multiple routers in the OSPF protocol zones

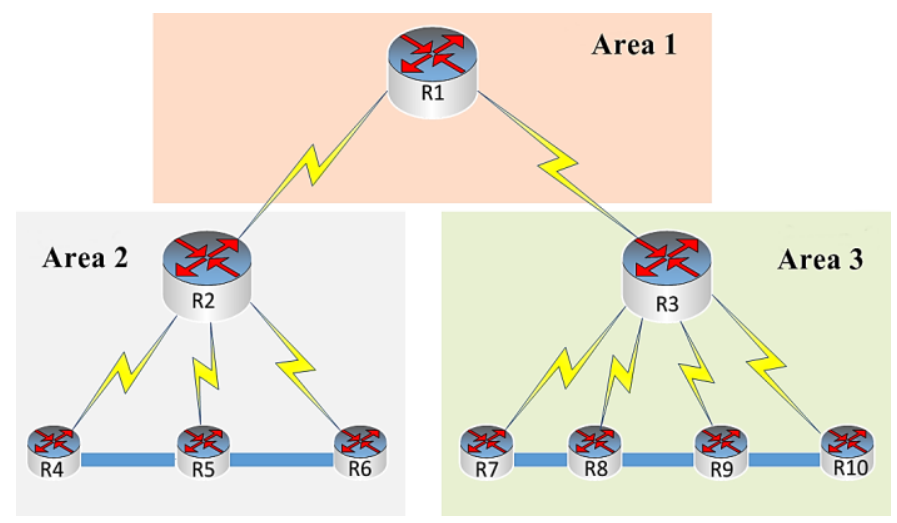

Fig. 9. Connecting routers multiple zones in the protocol IS-IS

Figure 9 presents example of connecting several routers, located in several different zones with using routing protocol IS-IS. The difference with connecting the routers using OSPFprotocol is in the fact that the routers of 1-2 level are located not at the border of two zones, but in some zone. In example given by the figure, the routers R2 and R3 are the routers of 12 level. The routers of user's access level, in this case R4Rr10, are the routers of level 1 . The $\mathrm{R} 1$ router is the router of level 2. Another difference from OSPF-protocol is the fact that the basic zone does not necessarily have the number 0 , it can have any number.

\section{A. The comparison of the OSPF and IS-IS protocols}

To obtain information about the operation of the OSPF protocol, a testbed was used, the diagram of which is presented in Figure 10. 


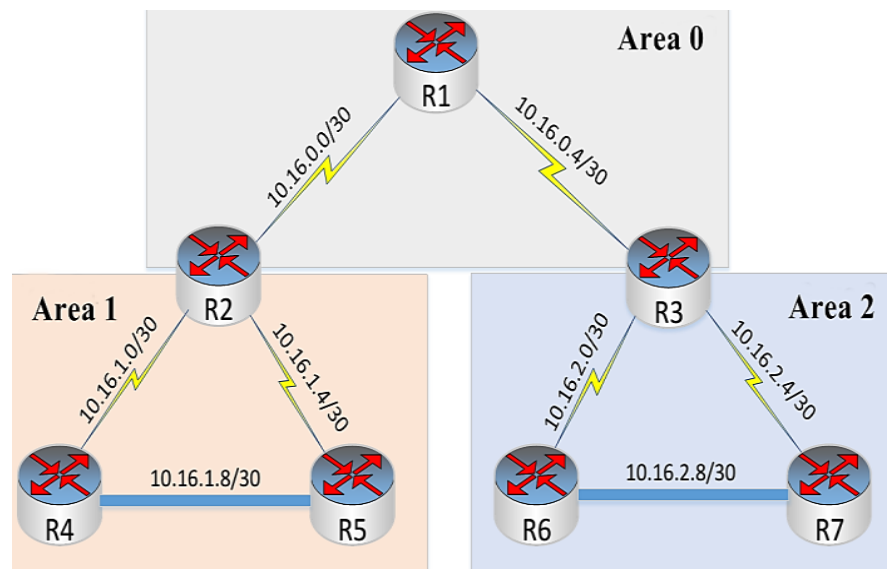

Fig. 10. The model of the data transmission testbed model

To obtain the performance characteristics of the routers, a scheme with 3 areas was used - two standard areas (areas 1 and 2) and a backbone area (area 0). Accordingly, the R1 router is located in the backbone area and ensures the transfer of information from the area border routers R2 and R3 of the standard areas. The R4-R7 routers are user access level routers. For the comparison of the efficiency of the OSPF and IS-IS protocols in terms of occupied memory and CPU resources, required for the procession of routes, of the most interest are routing tables and databases, stored in the memory of area border routers [20].

The routing table for the $\mathrm{R} 3$ router is presented below.

$\mathrm{R} 3 \#$ show ip route

10.0.0.0/8 is variably subnetted, 10 subnets, 2 masks

C 10.0.2.1/32 is directly connected, Loopback0

O 10.16.2.8/30 [110/65] via 10.16.2.6, 00:00:48, Serial0/2

[110/65] via 10.16.2.2, 00:00:48, Serial0/1

C 10.16.0.8/30 is directly connected, FastEthernet0/0.401

O IA 10.16.1.8/30 [110/193] via 10.16.0.5, 00:00:48, Serial0/0

C 10.16.2.0/30 is directly connected, Serial0/1

O 10.16.0.0/30 [110/128] via 10.16.0.5, 00:00:53, Serial0/0

O IA 10.16.1.0/30 [110/192] via 10.16.0.5, 00:00:50, Serial0/0

C 10.16.2.4/30 is directly connected, Serial0/2

C 10.16.0.4/30 is directly connected, Serial0/0

O IA 10.16.1.4/30 [110/192] via 10.16.0.5, 00:00:50, Serial0/0

It can be seen that the routing table even of such a small testbed, which includes only data transmission devices without target devices, contains 10 networks, stored in the memory of area border routers. As the areas are not stub, each router stores the same routing tables, for example, the routing table, stored in the memory of the user access level router R4, contains the same number of entries; this table is presented below.

$\mathrm{R} 7$ \#show ip route

10.0.0.0/8 is variably subnetted, 10 subnets, 2 masks

C 10.0.2.3/32 is directly connected, Loopback0

C 10.16.2.8/30 is directly connected, FastEthernet0/0.421

O IA 10.16.1.8/30 [110/257] via 10.16.2.5, 00:42:23, Serial0/0

O 10.16.2.0/30 [110/65] via 10.16.2.9, 00:42:23,

FastEthernet0/0.421
O IA 10.16.0.0/30 [110/192] via 10.16.2.5, 00:42:23, Serial0/0 O IA 10.16.1.0/30 [110/256] via 10.16.2.5, 00:42:25, Serial0/0 C 10.16.2.4/30 is directly connected, Serial0/0 O IA 10.16.0.4/30 [110/128] via 10.16.2.5, 00:42:25, Serial0/0 O IA $10.16 .1 .4 / 30$ [110/256] via 10.16.2.5, 00:42:25, Serial0/0

Area border routers store databases, which contain data on the backbone area and the area to which they are connected; therefore, the databases of area border routers have the largest volume and occupy a large amount of memory. The database, stored in the memory of the area border router, is presented below.

r3\#show ip ospf database

OSPF Router with ID (10.0.2.1) (Process ID 1)

Router Link States (Area 0)

Link ID ADV Router Age Seq\# Checksum Link count 10.0.0.1 10.0.0.1 1823 0x80000005 0x0066FF 4 10.0.1.1 10.0.1.1250 0x80000005 0x008FB9 2 10.0.2.1 10.0.2.1 1824 0x80000003 0x00122F 2

Summary Net Link States (Area 0)

Link ID ADV Router Age Seq\# Checksum 10.16.1.0 10.0.1.1 1017 0x80000003 0x004096 10.16.1.4 10.0.1.1 1017 0x80000003 0x0018BA 10.16.1.8 10.0.1.1 1017 0x80000003 0x00F9D3 10.16.2.0 10.0.2.1818 0x80000005 0x002AA8 10.16.2.4 10.0.2.1 818 0x80000004 0x0004CB 10.16.2.8 10.0.2.1 818 0x80000002 0x00E9E2

Router Link States (Area 2)

Link ID ADV Router Age Seq\# Checksum Link count 10.0.2.1 10.0.2.1 818 0x80000003 0x0062F4 4 10.0.2.2 10.0.2.2 $8060 \times 80000005$ 0x007D67 3 10.0.2.3 10.0.2.3 794 0x80000005 0x006C6D 3

Net Link States (Area 2)

Link ID ADV Router Age Seq\# Checksum 10.16.2.10 10.0.2.3 1049 0x80000003 0x006C7C

Summary Net Link States (Area 2)

Link ID ADV Router Age Seq\# Checksum 10.16.0.0 10.0.2.1 821 0x80000002 0x00C8CE

10.16.0.4 10.0.2.1 821 0x80000002 0x001EB5

10.16.1.0 10.0.2.18210x80000002 0x004016

10.16.1.4 10.0.2.1821 0x80000002 0x00183A 10.16.1.8 10.0.2.1 821 0x80000002 0x00F953

As can be seen, area border routers need to store a large amount of information, related to several areas of the data transmission network, which occupies a large amount of memory.

The database, stored by the user access level router, is presented below.

r4\#show ip ospf database

OSPF Router with ID (10.0.2.3) (Process ID 1) Router Link States (Area 2) 
Link ID ADV Router Age Seq\# Checksum Link count

10.0.2.1 10.0.2.1 897 0x80000003 0x0062F4 4

10.0.2.2 10.0.2.2 $8800 \times 800000050 x 007 D 673$

10.0.2.3 10.0.2.3 867 0x80000005 0x006C6D 3

Net Link States (Area 2)

Link ID ADV Router Age Seq\# Checksum

10.16.2.10 10.0.2.3 1122 0x80000003 0x006C7C

Summary Net Link States (Area 2)

Link ID ADV Router Age Seq\# Checksum

10.16.0.0 10.0.2.1 897 0x80000002 0x00C8CE

10.16.0.4 10.0.2.1 897 0x80000002 0x001EB5

10.16.1.0 10.0.2.1 897 0x80000002 0x004016

10.16.1.4 10.0.2.1 897 0x80000002 0x00183A

10.16.1.8 10.0.2.1 897 0x80000002 0x00F953

The database, which is stored in the memory of the user access level router, contains the routes to the networks, belonging to other areas, and occupies a large amount of the router's memory. To compare the efficiency of memory usage by the routers, which use the IS-IS routing protocol, a testbed was used, the model of which is presented in Figure 11.

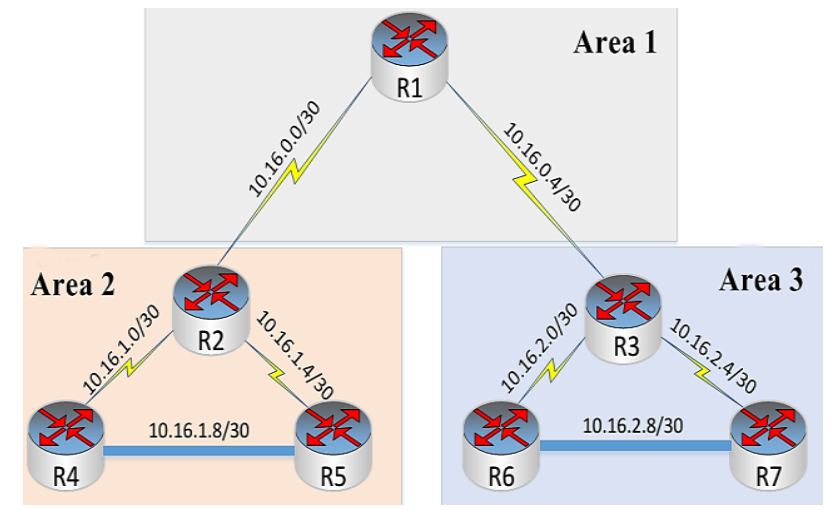

Fig. 11. The model of the data transmission testbed

As can be seen from Figure 11, routers R2 and R3, which are the level 1-2 routers, are not located on the border between two areas, but belong to a single area, though they are used for transferring data between the standard area and the backbone area. The R1 router, located in the backbone area and transferring data from one standard area into another standard area (in this case, areas 2 and 3), is located in area 1. The backbone area is present, but it doesn't necessarily have a number 0 , which is reflected in the diagram of the routing testbed. The $\mathrm{R} 1$ router $\mathrm{R} 1$ is a level 2 router, the routers $\mathrm{R} 4$ R7 are level 1 routers and can only transfer information between directly connected devices of the same level. For the communication with devices from other areas, they need to use level 1-2 routers, which store information on the routes of the area in which they are located (level 1 routes), as well as on the routes of the backbone area (level 2 routes). below.

The routing table of the level 1-2 router is presented r3\#show ip route

10.0.0.0/8 is variably subnetted, 10 subnets, 2 masks
C 10.0.2.1/32 is directly connected, Loopback0

i L1 10.16.2.8/30 [115/20] via 10.16.2.6, Serial0/2

$[115 / 20]$ via 10.16 .2 .2 , Serial0/1

i L2 10.16.0.8/30 [115/30] via 10.16.0.5, Serial0/0

i L2 10.16.1.8/30 [115/40] via 10.16.0.5, Serial0/0

C 10.16.2.0/30 is directly connected, Serial0/1

i L2 10.16.0.0/30 [115/20] via 10.16.0.5, Serial0/0

i L2 10.16.1.0/30 [115/30] via 10.16.0.5, Serial0/0

C 10.16.2.4/30 is directly connected, Serial0/2

C 10.16.0.4/30 is directly connected, Serial0/0

i L2 10.16.1.4/30 [115/30] via 10.16.0.5, Serial0/0

The topology table of the area border router contains entries of 10 networks, the same as the topology table for a similar testbed, using the OSPF routing protocol. In addition to the information on the available networks and routes, through which they are available, there is also information on the level of the topology table, in which the information data is stored; this is indicated by the code symbols L1 and L2.

The routing table of the level 1 router is presented below.

r6\#show ip route

10.0.0.0/8 is variably subnetted, 7 subnets, 3 masks

C 10.0.2.2/32 is directly connected, Loopback0

C 10.16.2.8/30 is directly connected, FastEthernet0/0.421

C 10.16.2.0/30 is directly connected, Serial0/0

i L1 10.16.2.4/30 [115/20] via 10.16.2.10, FastEthernet0/0.421

[115/20] via 10.16.2.1, Serial0/0

i L1 10.16.0.4/30 [115/20] via 10.16.2.1, Serial0/0

C 10.32.2.0/28 is directly connected, FastEthernet0/1.121

C 10.32.2.16/28 is directly connected, FastEthernet0/1.122

iL1 0.0.0.0/0 [115/10] via 10.16.2.1, Serial0/0

It can be seen that the routing table contains 7 entries, which is less than in case of using the OSPF protocol; in the latter case the routing table contained 10 entries. The level 1 router only stores the information on level 1 routers, which is confirmed by the fact that only the entries with a L1 tag are present.

The database of the IS-IS protocol is also smaller than the OSPF databases. The database of the level 1-2 router is presented below.

r3\#show isis database

IS-IS Level-1 Link State Database:

LSPID LSP Seq Num LSP Checksum LSP Holdtime ATT/P/OL

r3.00-00*0x00000006 0x64D9 577 1/0/0

r6.00-00 0x00000005 0x9265 518 0/0/0

r7.00-00 0x00000005 0x7627 626 0/0/0

IS-IS Level-2 Link State Database:

LSPID LSP Seq Num LSP Checksum LSP Holdtime ATT/P/OL

r1.00-00 0x00000005 0x90A6 658 0/0/0

r2.00-00 0x00000007 0x15AC 407 0/0/0

r3.00-00* 0x00000007 0x7399 697 0/0/0

It should be noted that the database is smaller than the OSPF database and contains records of not all the routers in 
the network, but only those which belong to the same area as the level 1-2 router, and also of the level 2 router and the channels of communication with it.

The database of the level 1 router is presented below.

r6\#show isis database

IS-IS Level-1 Link State Database:

LSPID LSP Seq Num LSP Checksum LSP Holdtime ATT/P/OL

r3.00-00 0x00000006 0x64D9 344 1/0/0

r6.00-00*0x00000006 0x9066 1046 0/0/0

r7.00-00 0x00000005 0x7627 396 0/0/0

It should be noted that the level 1 router only stores information on the routers of the same level (R6 and R7), located in the same area, as well as on the level 1-2 router (R3). Thus, the database of the user access level router, which uses the IS-IS routing protocol, occupies a much smaller amount of memory than the database of the router, using the OSPF routing protocol.

\section{B. Conclusions of the efficiency of use}

When considering IS-IS protocol, it is necessary to remember that in many aspects it is similar to OSPF-protocol and, besides it is routing protocol by the channel status, it uses Dijkstra's algorithm of searching for the shortest way, mailing the packages on the channels status and many others. At that, there are many differences between routing protocols IS-IS and OSPF, first of all because the IS-IS is not using IPaddresses as the routs. On the one hand, it allows to use IS-ISprotocol for operating in IPv6 networks, where OSPF version 2 is not capable to do that, and to resolve this problem, the OSPF-protocol version 3 has been developed. However, on the other hand, when using IPv4, adjusting routing by means of IS-IS-protocol will cause necessity to study sufficient volume of information and to use unusual methods of routing adjustment.

\section{CONCLUSION}

Having considered several options of modernization, including the revolutionary one - changing OSPF-protocol for IS-IS-protocol, and evolutionary one - changing parameters of OSPF-protocol, like: use of route information redistribution; use of dead-end zones; use not completely dead-end zones. It is necessary to make a conclusion on all pluses and minuses of the reviewed options of modernization and choose the best one among presented (Table 11).

All the options of existing routing system modernization have in common that all reviewed option allow to reduce the tables of routing being stored in memory of the routers located inside regular zones. Thus, the conclusion can be made that any of the reviewed options allows to resolve the main problem and to reduce load on the routers.

Rest of advantages are not that valuable to make a choice of their basis. To select the modernization option, it is necessary to review the disadvantages inherent to various options.
TABLE XI. THE PARAMETERS OF THE DEFAULT-INFORMATION ORIGINATE COMMAND

\begin{tabular}{|c|c|c|}
\hline $\begin{array}{c}\text { Option of } \\
\text { modernization }\end{array}$ & Advantages & Disadvantages \\
\hline $\begin{array}{l}\text { Use of route } \\
\text { information } \\
\text { redistribution }\end{array}$ & $\begin{array}{l}\text { Reduction of the tables of } \\
\text { topology and occupied by } \\
\text { them memory volumes in } \\
\text { the inner routers. } \\
\text { Possibility to conduct the } \\
\text { modernization on existing } \\
\text { equipment. }\end{array}$ & $\begin{array}{l}\text { Complicated adjustment } \\
\text { of the routing mechanism } \\
\text { on the transport- } \\
\text { peripheral nodes and on } \\
\text { the regional node. }\end{array}$ \\
\hline $\begin{array}{c}\text { Use of } \\
\text { completely } \\
\text { dead-end zones }\end{array}$ & $\begin{array}{l}\text { Simplicity of completely } \\
\text { dead-end zones adjusting. } \\
\text { Possibility to use } \\
\text { completely dead-end } \\
\text { zones on the existing } \\
\text { equipment. }\end{array}$ & $\begin{array}{l}\text { Impossibility to add } \\
\text { statistics routes inside the } \\
\text { completely dead-end } \\
\text { zones. } \\
\text { Impossibility to use } \\
\text { border routers of } \\
\text { autonomous } \\
\text { systems in the dead-end } \\
\text { zones. }\end{array}$ \\
\hline $\begin{array}{c}\text { Use of not } \\
\text { completely } \\
\text { dead-end zones }\end{array}$ & $\begin{array}{l}\text { Reduction of the tables of } \\
\text { topology and occupied by } \\
\text { them memory volumes in } \\
\text { the routers memory. } \\
\text { Possibility to transfer } \\
\text { external routs from not } \\
\text { completely dead-end } \\
\text { zone. }\end{array}$ & $\begin{array}{l}\text { Possible discrepancy } \\
\text { between standards of the } \\
\text { equipment operational } \\
\text { systems. } \\
\text { There is a danger that the } \\
\text { installed equipment will } \\
\text { not be possible to set for } \\
\text { joint operation. }\end{array}$ \\
\hline $\begin{array}{l}\text { Use of routing } \\
\text { protocol IS-IS }\end{array}$ & $\begin{array}{l}\text { Reduction of the routing } \\
\text { tables and data bases, } \\
\text { therefore - occupied by } \\
\text { them memory volumes in } \\
\text { the router memory. } \\
\text { Possibility to use in large } \\
\text { data transfer networks. } \\
\text { Easy scaling the existing } \\
\text { network. }\end{array}$ & $\begin{array}{l}\text { Difficulty to set routing } \\
\text { in the data transfer } \\
\text { network using UPv4 } \\
\text { addressing. } \\
\text { Impossibility to establish } \\
\text { communication between } \\
\text { the routers of level } 1 \text { and } \\
\text { level } 2 \text { without using } \\
\text { intermediate routers of } 1 \text { - } \\
2 \text { level. }\end{array}$ \\
\hline
\end{tabular}

Use of route information redistribution mechanism is rather complicated thing both during setting and further operation, plus it requires high qualification of the network engineer. The mechanism of completely dead-end zones is not that complicated in setting and in operation, but it does not allow adding statistics routes within the zones neither provide communication of the regular zone with the autonomous systems, thus reducing efficiency of data transfer network. The not completely dead-end zones, having all advantages of the completely dead-end zones, allows to contain within regular zones the border routers of the autonomous systems and thus to enhance flexibility of data transfer network. The minus is that there is a necessity appearing to use equipment with a modern operational system. Change the routing protocol OSPF for IS-IS protocol. This option is rather labor intensive and it requires use of very competent personnel, meaning high labor costs.

Therefore, the most advantageous option to effect the routing scheme seems to be the option using not completely dead-end zones, which does not require much efforts on implementation and support of the network functionality, as well as increasing data transfer network flexibility and possibility to transfer information from the regular zones into other autonomous systems. 


\section{REFERENCES}

[1] Kolbasinsky, D. B., 2013. Information Networks and TV Communications. Pp: 431.

[2] Makarov, S.V., V.V. Ostanin and I.V. Vaitkov, 2014. The Comparison of Routers by Firms Cisco, Juniper and Huawei. Modern Applied Science, 8(6).

[3] Al-Kasassbeh, M. and M. Adda, 2008. Analysis of Mobile Agents in Network Fault Management. Journal of Network and Computer Applications, 31: 699-711.

[4] Willie, E.C.G. and M.M. Tenorio, 2014. Considering Packet Loss in Fault-Tolerant OSPF Routing. IEEE Latin America Transaction, 12(2): 248-255.

[5] Xu, D., M. Chiang and J. Rexford, 2011. Link-State routing with Hopby-Hop Forwarding Can Achieve Optimal Traffic Engineering. IEEE/ACM Transactions on Networking, 19(6): 1717-1730.

[6] Solie, K. and L. Lynch, 2004. CCIE Practical Studies (1st ed.). Cisco Press.

[7] Nazri, M.I. and A.M. Zin, 2008. Emulation Network Analyzer Development for Campus Environment and Comparison between OPNET Applicatio and Hardware Network Analyzer. European Journal of Scientific Research, 24(2): 270-291.

[8] Al-Kasassbeh, M. and M. Adda, 2009. Network Fault Detection with Wiener Filter-Based Agent. Journal of Network and Computer Applications, 4(32).

[9] Guo, Y., Z. Wang, X. Yin, X. Shi and J. Wu, 2014. Traffic Engineering in SDN/OSPF Hybrid Network. In Proceedings of the 22nd IEEE International Conference on Network Protocols, pp: 563-568.

[10] Guo, H., W. Su, H. Zhang and S.-Y. Kuo, 2011. On the Convergence Condition and Convergence Time of BGP. Computer Communications, 34(2): 192-199.
[11] Fengxiang, Z. and A.B.E. Shunji, 2006. A DoS/DDoS Attacks Detection Scheme Based on In/Out Traffic Proportion. Information and Communication Engineers, 105: 7-11.

[12] Pang, Q., S.C. Liew, C.P. Fu, W. Wang and V.O. Li, 2003. Performance Study of TCP Veno over WLAN and RED Router. In Global Telecommunications Conference, 2003. GLOBECOM '03. IEEE (Volume 6), pp: 3237-3241.

[13] Qu, H., Z.Yi and S.X. Yang, 2014. Efficient Shortest-Path-Tree Computation in Network Routing Based on Pulse-Coupled Neural Networks. IEEE Transactions on Cybernetics, 43(3): 995-1010.

[14] Rosenberg, E. and J. Uttaro, 2013. A Fast Re-Route Method. IEEE Communications Letters, 17(8): 1656-1659.

[15] Bouillard, A., C. Jard and A. Junier, 2014. The Impact of Initial Delays in OSPF Routing. Communication in Computer and Information Science, 456: 37-57.

[16] Altin, A., B. Fortz, M. Thorup and H. Umit, 2013. Intra-Domain Traffic Engineering with Shortest Path Routing Protocols. Annals of Operations Research, 204(1): 65-95.

[17] Thai, B., R. Wan, A. Seneviratne and T. Rakotoarivelo, 2003. Integrated Personal Mobility Architecture: A Complete Personal Mobility Solution. Mobile Networks and Applications, 8(1): 27-36.

[18] Huh, I., J.Y. Lee and B.C. Kim, 2006. Decision of Maximum Congestion Window size for TCP performance Improvement by Bandwidth and RTT measurement in Wireless Multi-hop Networks. International Journal of Information Processing Systems.

[19] Nazri, M.I. and A.M. Zin, 2008. Measurement and Characterization of Network Traffic Utilization between Real Network and Simulation Modeling in Heterogeneous Environment. International Journal of Computer Science and Network, 8(3): 326-337.

[20] Vishwanath Member, A., K. Hinton, R.W.A. Ayre and R.S. Tucker, 2014. Modeling Energy Consumption in High-Capacity Routers and Switches. IEEE Journal on Selected Areas in Communication, 32(8): 1524-1532. 